\title{
Xenotransmission of the socioeconomic gradient in health? A population based study
}

\author{
Jamaluddin Moloo, Kirby L Jackson, Jennifer L Waller, Robert E McKeown, Cheryl L Addy, \\ Steven P Cuffe, Carol Z Garrison
}

Editorial by Davey Smith and Bonnett

Department of Medicine, 2 Medical Park, Room 506,

University of South

Carolina School of

Medicine,

Columbia,

SC 29203, USA

Jamaluddin Moloo,

assistant professor

Department of

Epidemiology and

Biostatistics,

University of South

Carolina School of

Public Health,

Columbia,

SC 29208, USA

Kirby L Jackson,

instructor

Jennifer L Waller,

assistant professor

Robert E McKeown,

assistant professor

Cheryl L Addy,

associate professor

Department of

Neuropsychiatry

and Behavioral

Science, University

of South Carolina

School of Medicine,

Columbia

Steven P Cuffe,

associate professor

Office of the

Provost, University

of Louisville,

Louisville, KY

40202, USA

Carol Z Garrison,

provost

Correspondence to:

Dr Moloo

jmoloo@sc.edu

BMJ 1998;317:1686
The presence of a socioeconomic gradient in health has been documented extensively in humans. ${ }^{12}$ Social hierarchy has also been found to be associated with the health of non-human species, as in a study of macaques, in which development of coronary artery occlusion was associated with social hierarchy. ${ }^{3}$ However, to our knowledge, transmission of the social gradient in health across species has never been reported. We investigated whether the socioeconomic gradient in health could be transmitted from humans to their pets.

\section{Participants, methods, and results}

The present research was part of a larger study on depression and suicidal behaviours among adolescents. In this study, cross sectional data were collected annually between 1986 and 1988 from school students in a single, socioeconomically diverse, suburban district in the southeastern United States. Students completed a self administered questionnaire, which included the highest educational level of a parent as a marker of socioeconomic status and the frequency of experiencing the "death of a pet" during the preceding 12 months. We examined the mean frequency of experiencing the death of a pet across socioeconomic strata. To minimise confounding we controlled for race through multivariate analysis of variance.

Altogether, 3419 students completed the survey; the response rate each year was at least $98 \%$. The sample was reduced to $2954(86.4 \%)$ after exclusion of students who did not report parental educational level. Analysis with the $t$ test found no significant difference in mean frequency of experiencing death of a pet between students who reported parental education level and those who did not. The sample was equally divided between males and females; students were aged $11-18$ years; $16 \%$ of students were black; and $67 \%$ of students had parents with less than 4 years' university education.

We found an association between socioeconomic status and reported death of a pet $(\mathrm{P}=0.02)$ (table). The mean frequency of reporting the death of a pet was $25 \%$ greater among students whose parents had not finished high school compared with students whose parents had completed at least 4 years of university (0.85 $v 0.68)$. Controlling for race did not alter the results.

\section{Comment}

These findings may be explained by higher rates of pet ownership among students of lower socioeconomic status; as depression was the focus of the study, students were not asked if they owned a pet. However, in the United States ownership of any pet is positively
Mean frequency of reported death of a pet by socioeconomic status (parental education)

\begin{tabular}{lc} 
Parental education & Mean frequency* \\
\hline Less than high school & 0.85 \\
\hline High school & 0.72 \\
\hline Technical school or $<4$ years at university & 0.71 \\
\hline$\geqslant 4$ years at university & 0.68 \\
\hline
\end{tabular}

${ }^{\star} \mathrm{P}=0.02$ after white or black race was controlled for.

associated with household income, and this relation exists for dogs, cats, or "small animals"-namely, hamsters, gerbils, etc. ${ }^{4}$ Thus, neither rates of ownership nor type of pet owned seems to explain the transmission of the gradient in health from humans to their pets. Rather, the "mortality" differences in this study are probably an underestimate of the true socioeconomic disparity.

Explanations for the apparent xenotransmission of the health gradient probably include all of the factors that contribute to disparities in health among humans, such as access to health care, nutritional status, environmental exposure, and social support. It is also conceivable that health related behaviours of individual pets are influenced by the social position of their owners, highlighting the profound impact of social position on health related behaviours of both human and non-human species.

Evans succinctly summarises the impact of socioeconomic status on health by stating: "Top people live longer." ${ }^{5}$ As is often the case, such simplifications mask important details; "top people and their pets live longer" may be more accurate.

Contributors: JM initiated and coordinated the formulation of the study hypothesis and participated in data analysis and writing of the paper. KLJ participated in the study design, data collection, analysis, and editing of the paper. JLW participated in the data collection, data analysis, and editing. REMcK, CLA, and SPC participated in the study design, data collection, and editing. CZG, the principal investigator, initiated the depression research project and participated in the design, data collection, and editing.

Funding: This research was supported by the National Institute of Mental Health (grant No MH40363).

Competing interests: None.

1 Black D, Morris JN, Smith C, Townsend P. The Black report. London: Pelican, 1982.

2 Smith GD, Carroll D, Rankin S, Rowan D. Socioeconomic differentials in mortality: evidence from Glasgow graveyards. BMJ 1992;305:1554-7.

3 Hamm TE, Kaplan JR, Clarkson TB, Bullock BC. Effects of gender and social behavior on the development of coronary artery atherosclerosis in cynomolgous macaques. Atherosclerosis 1983;48:221-33.

4 American Pet Products Manufacturers Association. 1996-1997 APPMA national pet owners survey. Greenwich: APPMA, 1997.

5 Evans RG. Introduction. In: Evans RG, Barer ML, Marmor TR, eds. Why are some people healthy and others not? New York: Walter de Gruyter, 1994:3. 